\title{
A Case of Zenker's Diverticulum in a Patient with Tight Esophageal Peptic Stricture
}

\author{
Abdulrahman M. Alkhormi ${ }^{1}$ Muhammad Y. Memon ${ }^{1}$ \\ ${ }^{1}$ Gastroenterology and Endoscopy Unit, Department of Medicine, \\ King Abdulaziz Medical City, Riyadh, Saudi Arabia
}

\begin{abstract}
Address for correspondence Abdulrahman M. MD, Alkhormi, Gastroenterology and Endoscopy Unit, Department of Medicine, King Abdulaziz Medical City, P.O. box 22490, Riyadh 11426, Saudi Arabia (e-mail: Dr_abuturkey@hotmail.com).
\end{abstract}

Abstract
Keywords
- Zenker's diverticulum
- peptic stricture
- gastroesophageal
reflux disease

Zenker's diverticulum (ZD) is a posterior Sac like outpouching of the hypopharyngeal mucosa and submucosa through Killian's triangle, which is an area of muscular weakness between the transverse fibers of the cricopharyngeus muscle and the oblique fibers of the lower inferior constrictor muscle. ZD usually presents with swallowing difficulties, regurgitation of undigested food, choking, halitosis, weight loss, and respiratory symptoms due to chronic aspiration. Several esophageal pathologies have been reported in association with ZD. These include cervical esophageal webs, upper esophageal stenosis, and hiatus hernia. Herein, we report a case of ZD in association with severe gastroesophageal reflux disease and tight lower esophageal peptic stricture.

\section{Introduction}

Zenker's diverticulum (ZD) is a posterior Sac like outpouching of the hypopharyngeal mucosa and submucosa through Killian's triangle, which is an area of muscular weakness between the transverse fibers of the cricopharyngeus muscle and the oblique fibers of the lower inferior constrictor muscle. ${ }^{1}$ It was first described by Ludlow in 1767. ${ }^{2}$ Zenker et al subsequently reported their own cases and reviewed the world literature on this entity in 1877; since then, the condition has been referred to as $\mathrm{ZD} .{ }^{3} \mathrm{ZD}$ is a rare condition; however, it is more common in Western rather than in Asian populations. ${ }^{4}$ The reported prevalence of ZD in the United States general population is 0.01 to $0.11 \%{ }^{5}$ It is more common in males, especially in the elderly population, that is, those in their seventh decade of life or later. ${ }^{6} \mathrm{ZD}$ usually presents with swallowing difficulties, regurgitation of undigested food, choking, halitosis, weight loss, and respiratory symptoms due to chronic aspiration. The larger the pouch, the more prominent the symptoms. ${ }^{7}$ ZD may cause dysphagia due to incomplete opening of the upper esophageal sphincter (UES) or through external compression of the cervical esophagus by the diverticulum itself. ${ }^{8}$ The underlying etiology and pathophysiology of ZD are not well understood. Several hypotheses have been proposed to explain the pathophysiology. These include spasm of the cricopharyngeus muscle with resultant breach through the weakened area, ${ }^{9}$ incoordination of the pharyngeal muscles, congenital weakness, and traction or suction diverticulum..$^{10,11}$ However, the most widely accepted theory at present is the normal relaxation but inadequate opening of the UES. ${ }^{22}$ Several associated esophageal pathologies have been reported in association with ZD. These include cervical esophageal webs, ${ }^{13,14}$ upper esophageal stenosis, ${ }^{15}$ and hiatus hernia. ${ }^{16-18}$

Herein, we report a case of ZD in association with severe gastroesophageal reflux disease (GERD) and tight lower esophageal peptic stricture.

\section{Case Report}

A 62-year-old woman with a medical history of diabetes mellitus, hypertension, hypothyroidism, and end-stage renal disease on hemodialysis presented to the emergency room (ER) with hematemesis and melena. Esophagogastroduodenoscopy (EGD) revealed GERD with grade $C$ esophagitis (Los Angeles classification). There were no other abnormalities. She was discharged home on esomeprazole $(40 \mathrm{mg}$ orally once daily) and antireflux measures with a follow-up appointment at the gastroenterology clinic. However, she 
was lost to follow-up with the gastroenterologist for 2 years. She presented to the ER after two years of first admission with progressive dysphagia, intractable vomiting, and weight loss over the past 2 to 3 months. On physical examination (PE), she was emaciated with moderate dehydration. The rest of the PE revealed no abnormalities. After hydration, EGD was performed, upon which intubation of the esophagus was relatively difficult, with the finding of small ZD on cautious upper esophageal examination (-Fig. 1). Further examination of the esophagus revealed an ulcerated lower esophageal stricture with proximal dilatation (-Fig. 2). The stricture was too tight to bypass, leading to failure of gastric and duodenal examination. Biopsies from the stricture did not show any evidence of malignancy. Barium swallow showed a small ZD $(<2 \mathrm{~cm})$, dilated esophagus along with tight, short, and smooth distal esophageal stricture ( - Fig. 3 ). Computed tomography $(\mathrm{CT})$ also demonstrated the distal esophageal stricture and thickening with no lymphadenopathy. The stricture was refractory to dilatation with a controlled radial expansion balloon and was eventually managed with a fully covered self-expanding metallic stent.

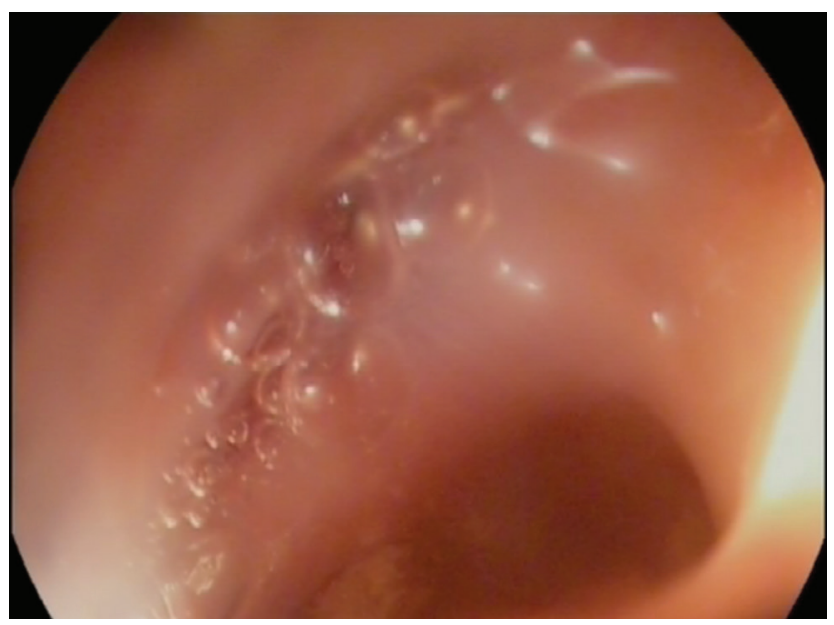

Fig. 1 Small Zenker's diverticulum.

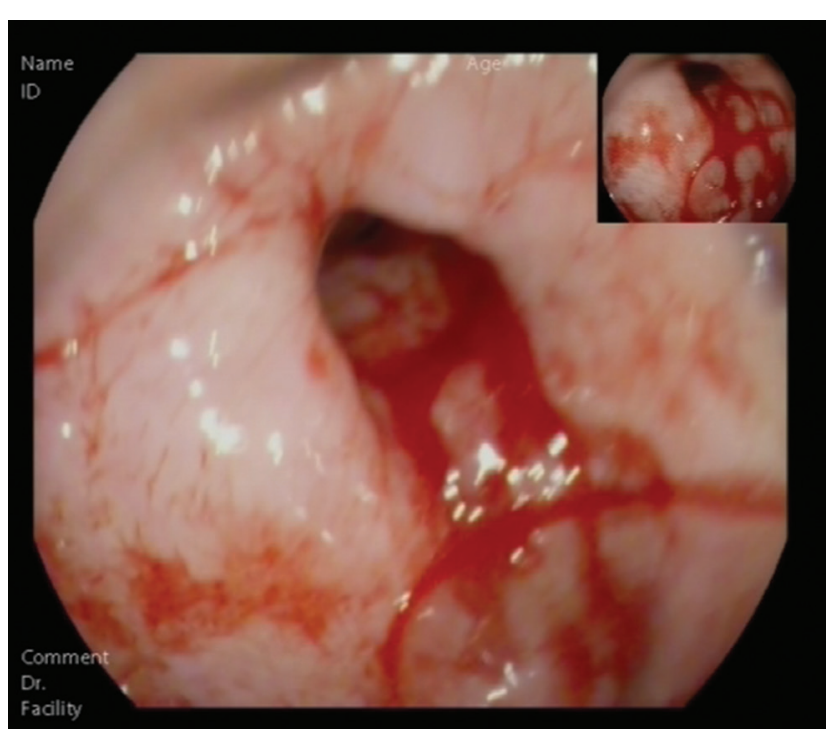

Fig. 2 Distal esophageal stricture.

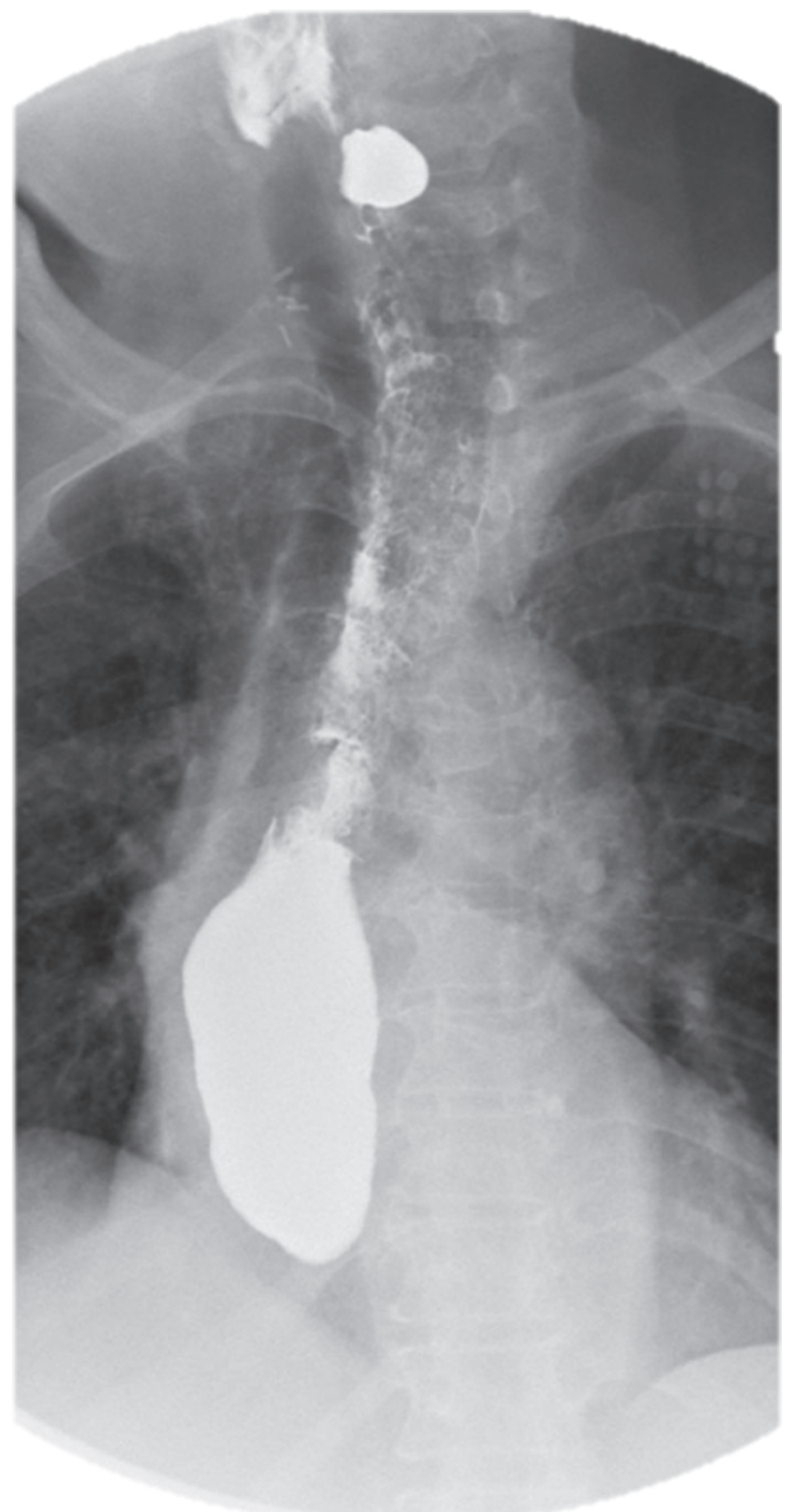

Fig. 3 Barium swallow: Zinker's diverticulum, esophageal stricture, and dilated proximal esophagus.

\section{Discussion}

There is controversy about the causal relationship between ZD and GERD. Several investigators have found an explicit association between GERD and ZD. ${ }^{19-21}$ The underlying mechanism of ZD development in GERD is poorly understood. Sasaki et al hypothesized that acid reflux promotes longitudinal esophageal shortening, which ultimately results in an increased risk of the development of hypopharyngeal mucosa and submucosa herniation. ${ }^{21}$ However, Feussner and Siewert believed that GERD plays no role in the pathogenesis of ZD; instead, they believed that autochthonic structural lesions to the UES muscle fibers or other as yet unknown reasons are more probable. ${ }^{22}$ Our patient had severe GERD, and it is highly possible that ZD had developed secondary to this. 
ZD has never been reported in association with a lower esophageal peptic stricture. In our patient, the temporal relationship between the distal esophageal peptic stricture and ZD development suggests that the distal esophageal obstruction caused by peptic stricture contributed to the ZD development through increased intraesophageal pressure. This agrees with Negus's hypothesis of stenosis-induced increased intraluminal pressure, leading to $\mathrm{ZD}$ development. ${ }^{23}$ The hypothesis of distal esophageal obstruction and increased intraluminal pressure may also explain, at least partially, the association reported between ZD and esophageal achalasia. ${ }^{24,25}$ In achalasia, however, esophageal aperistalsis also suggests obstruction at the UES level.

According to Morton-Bartney's classification, ZD is divided into small $(<2 \mathrm{~cm})$, medium (between 2 and $4 \mathrm{~cm}$ ), and large $(>4 \mathrm{~cm}) .^{7}$ The ZD in our patient was small and is not expected to be the reason for her symptoms. Treatment of her GERD and lower esophageal stricture has relieved the dysphagia and will probably halt the progression of the ZD. However, further follow-up is needed to confirm our hypothesis.

\section{Conflict of Interest}

None.

\section{References}

1 Bizzotto A, Iacopini F, Landi R, Costamagna G. Zenker's diverticulum: exploring treatment options. Acta Otorhinolaryngol Ital 2013;33(4):219-229

2 Ludlow A. A case of obstructive deglutition from a preternatural dilatation of a bag formed in pharynx. Med Observation Inquiries. 1767;3:85

3 Zenker FA, Van Ziemssen H. Krankheiten des oesophagus. In: Handbuch der specielen pathologie und therapie. Van Ziemssen H, ed. Leipzig: FC Vogel; 1877

4 van Overbeek JJM. Meditation on the pathogenesis of hypopharyngeal (Zenker's) diverticulum and a report of endoscopic treatment in 545 patients. Ann Otol Rhinol Laryngol 1994;103(3):178-185

5 Watemberg S, Landau O, Avrahami R. Zenker's diverticulum: reappraisal. Am J Gastroenterol 1996;91(8):1494-1498

6 Maran AGD, Wilson JA, Al Muhanna AH. Pharyngeal diverticula. Clin Otolaryngol Allied Sci 1986;11(4):219-225
7 Siddiq MA, Sood S, Strachan D. Pharyngeal pouch (Zenker's diverticulum) Postgrad Med J 2001;77(910):506-511

8 Law R, Katzka DA, Baron TH. Zenker's diverticulum. Clin Gastroenterol Hepatol 2014;12(11):1773-1782, quiz e111-e112

9 Sutherland HD. Cricopharyngeal achalasia. J Thorac Cardiovasc Surg 1962;43:114-126

10 van Overbeek JJ. Pathogenesis and methods of treatment of Zenker's diverticulum. Ann Otol Rhinol Laryngol 2003;112(7):583-593

11 Barclay AE. Der normale schlingmechanisms. Acta Radiol 1932;13:91-110

12 Cook IJ, Gabb M, Panagopoulos V, et al. Pharyngeal (Zenker's) diverticulum is a disorder of upper esophageal sphincter opening. Gastroenterology 1992;103(4):1229-1235

13 Mercer CD, Hill LD. Esophageal web associated with Zenker's diverticulum: a possible cause of continuing dysphagia after diverticulectomy. Can J Surg 1985;28(4):375-376

14 Low DE, Hill LD. Cervical esophageal web associated with Zenker's diverticulum. Am J Surg 1988;156(1):34-37

15 Skinner EF, Page G. Esophago-diverticulostomy for stenosis of upper esophagus associated with Zenker's diverticulum. Am Surg 1958;24(11):806-810

16 Ponzoli VA Jr. Zenker's diverticulum: a review of pathogenesis and presentation of 25 cases. South Med J 1968;61(8):817-821

17 Smiley TB, Caves PK, Porter DC. Relationship between posterior pharyngeal pouch and hiatus hernia. Thorax 1970;25(6):725-731

18 Gage-White L. Incidence of Zenker's diverticulum with hiatus hernia. Laryngoscope 1988;98(5):527-530

19 Delahunty JE, Margulies SI, Alonso WA, Knudson DH. The relationship of reflux esophagitis to pharyngeal pouch (Zenker's diverticulum) formation. Laryngoscope 1971;81(4):570-577

20 Hunt PS, Connell AM, Smiley TB. The cricopharyngeal sphincter in gastric reflux. Gut 1970;11(4):303-306

21 Sasaki CT, Ross DA, Hundal J. Association between Zenker diverticulum and gastroesophageal reflux disease: development of a working hypothesis. Am J Med 2003;115(Suppl 3A):169S-171S

22 Feussner H, Siewert JR. Zenker's diverticulum and reflux. Hepatogastroenterology 1992;39(2):100-104

23 Negus VE. Pharyngeal diverticula; observations on their evolution and treatment. Br J Surg 1950;38(150):129-146

24 Sayles M, Harrison L, McGlashan JA, Grant DG. Zenker's diverticulum complicating achalasia: a 'cup-and-spill' oesophagus. Bmj Case Reports. 2013;2013:bcr2013200702.

25 Jones B, Donner MW, Rubesin SE, Ravich WJ, Hendrix TR. Pharyngeal findings in 21 patients with achalasia of the esophagus. Dysphagia 1987;2(2):87-92 